sciendo

REDKE VRSTE PTIC V SLOVENIJI

V LETU 2017 - POROČILO

NACIONALNE KOMISIJE ZA

REDKOSTI

\section{Rare birds in Slovenia in 2017 - Slovenian Rarities Committee's Report}

\section{Jurij Hanžel ${ }^{1}$, Mitja Denac ${ }^{2}$}

1 Židovska ulica 1, SI-1000 Ljubljana, Slovenija, e-mail: jurij.hanzel@gmail.com

2 Mala Slevica 2, SI - 1315 Velike Lašče, Slovenija, e-mail:mitja.denac@gmail.com

Poročilo Nacionalne komisije za redkosti (KRED) obravnava opazovanja redkih vrst med 1. 1. in 31 . 12. 2017 z dodanimi datumi iz leta 2018, če je bil osebek, prvič zabeležen v letu 2017, opazovan tudi v tem letu. Pri nekaterih vrstah so dodane dopolnitve za prejšnja leta. Komisija je delovala v naslednji sestavi (po abecednem vrstnem redu): Dejan Bordjan, Luka Božič, Jurij Hanžel (predsednik), Kajetan Kravos, Milan Vogrin.

Kot redke so obravnavane vrste, ki so bile kot take označene $\mathrm{v}$ Seznamu ugotovljenih ptic Slovenije s pregledom redkih vrst ter v zadnjem poročilu komisije (HANŽEL \& ŠERE 2011, HANŽEL 2016, HaNŽEL 2017a), ne glede na poprej veljavni kriterij, da je vrsta redka, če zanjo obstaja manj kot 10 podatkov, znanih po 1. 1. 1950. Seznam obravnavanih vrst in podvrst je dostopen na [http://cdn.ptice.si/ptice/2014/wp-content/ uploads/2015/10/2015_redke_vrste_si.xlsx].

Razvrstitev v kategorije, način navajanja kraja opazovanja in način navajanja virov sledijo smernicam v Seznamu. Upoštevane so sprotne spremembe iz poročil Taksonomske podkomisije komisije za redkosti pri Britanski zvezi ornitologov (British Ornithologists' Union Rarities Committee Taxonomic Subcommittee) (BOURC TSC). Taksonomska podkomisija je avgusta 2016 prenehala $\mathrm{z}$ delovanjem, zato je to poročilo prvo, kjer sledimo priporočilom Mednarodnega ornitološkega kongresa (International Ornithological Con- gress) (GILL \& DoNSKer 2018). Številki v oklepaju ob imenu posamezne vrste pomenita število opazovanj med 1. 1. 1950 in 31. 12. 2016 ter število opazovanih osebkov v istem časovnem obdobju. Takšno podajanje opazovanj je standardizirano po priporočilih Združenja evropskih komisij za redkosti (AERC - Association of European Rarities Committees) (AERC 2007). Za redke vrste, ki jih KRED obravnava od 1. 1. 2013 (37 dodatnih vrst, od tega 17 regionalnih redkosti), podatki o opazovanjih pred tem datumom niso sistematično zbrani, zato tudi niso predstavljeni. Iz istega razloga ta opazovanja niso oštevilčena. Opazovanja nacionalnih in regionalnih redkosti so predstavljena ločeno. Od 1. 1.2017 zaradi rednega pojavljanja ne obravnavamo več opazovanj srebrnega galeba Larus argentatus iz porečja Drave.

V letu 2017 smo zabeležili prve podatke iz kategorije A za belolično gos Branta leucopsis. Pozornost zbujajo tudi tretje opazovanje rdečevrate gosi Branta ruficollis, peto opazovanje za brkatega sera Gypaetus barbatus, lopatasto govnačko Stercorarius pomarinus in prekomorskega prodnika Calidris melanotos ter sedmo opazovanje za ploskokljunega liskonožca Phalaropus fulicarius in velikega galeba Larus marinus. Zaradi prilagoditve taksonomije smo seznamu dodali eno vrsto: njivska gos Anser fabalis je sedaj ločena na vrsti Anser fabalis in Anser serrirostris (vsebuje podvrsto rossicus, ki je bila opazovana v Sloveniji). Do vključno 31. 12. 2017 je bilo v Sloveniji ugotovljenih 390 vrst (375 v kategoriji A, 6 v kategoriji B, 9 samo v kategoriji $\mathrm{C}$; štiri vrste so uvrščene v kategoriji A in C hkrati). $\mathrm{V}$ kategoriji D je sedem vrst, v kategoriji E pa 39, med katerimi sta dve v podkategoriji E*. Vrste teh dveh kategorij niso del seznama.

V Dodatku 1 so dokumentarne fotografije opazovanj, ki doslej še niso bile objavljene $\mathrm{v}$ slovenskih tiskanih virih $\mathrm{z}$ navedenim krajem, datumom in številom osebkov.

\section{Potrjena opazovanja iz kategorije A / Accepted Category A records}

Rdečevrata gos Branta ruficollis (2, 2)

- 14. 1. 2017, Gajševsko jezero, 2 os. (Božıč 2017) 
Belolična gos Branta leucopsis (0, 0)

- $\quad$ 12. 1.2017, Babinci, 1 os. (R. ŠIšKo pisno)

- 14. 1. 2017, Amerika, Ormoško jezero, 1 os. (L. Božıčpisno)

- 28. 10.2017, zadrževalnik Medvedce, 1 os. (E. HoRvatpisno)

Labod pevec Cygnus cygnus $(13,27)$

- 1.-14. 2.2017, HE Brežice, reka Sava, 2 os. (D. KLENOVŠEK pisno)

\section{Beloliska Melanitta fusca}

- 11.3.2017, Fontanigge, Sečoveljske soline, 15 os. (B. BLAžıčpisno)

\section{Črna raca Melanitta nigra}

- 22. 2.-29. 3. 2017, Žovneško jezero, 1 q (M. GAMser, J. NovaKpisno)

\section{Zimska raca Clangula hyemalis}

- 7. 2.-29. 4. 2017, Šturmovci, Ptujsko jezero, $1-3$ os. (1 ð, 2 + $)$ (L. BožIČpisno)

- 8. 1.-7. 2. 2017, Ormoško jezero, 2 os. (1 ̊̉, 1 2cy ㅇ) (L. Božıčpisno)

- 17. 2. 2017, zadrževalnik Medvedce, 1 ô (M. GAMSERpisno)

- 9.-17.3.2017, Amerika, Ormoško jezero, 1 (L. Božıčpisno)

Ledni slapnik Gavia immer $(7,16)$

- 24. 11.-17. 12. 2017, Prule, Ljubljana, reka Ljubljanica, 1 ad. (Poljanec 2017)

Sredozemski viharnik Puffinus yelkouan

- 17.-18.6.2017, morje pred Piranom, do 75 os. (HANŽEL 2017b)

\section{Zlatouhi ponirek Podiceps auritus}

- $\quad$ 1. 1.2017, Fontanigge, Sečoveljske soline, 3 os. (M.SEŠLARpisno)

- 11. 2.-11. 3. 2017, Fontanigge, Sečoveljske soline, $1-11$ os. (B. BlažIČpisno)

- 9.4. 2017, Piran, 1 os. (J. HanžEl pisno)

- 20.9.2017, zadrževalnik Medvedce, 1 os. (M. GAMSER pisno)
- $\quad$ 25. 10. 2017, Šturmovci, Ptujsko jezero, 1 1cy (L. BožIČpisno)

- 3. 11. 2017, Turnišče, Ptujsko jezero, 2 ad. (L. Božıč, A., E., G. VRezec, P. VRh VReZec pisno) 10. 11. 2017, zadrževalnik Medvedce, 1 os. (M. GAMSERpisno)

- 10. 11. 2017, Ptuj, Ptujsko jezero, 2 ad. (L. BožIČpisno)

- 13. 12.2017, Turnišče, Ptujsko jezero, 2 ad. (L. BožIČpisno)

- 30. 12. 2017, Šturmovci, Ptujsko jezero, 2 ad. (L. BožIčpisno)

Plamenec Phoenicopterus roseus $(17,69)$

- 6. 10. 2017, Fontanigge, Sečoveljske soline, 1 os. (A. Božıčpisno)

Plevica Plegadis falcinellus

- 1.1.2017, Fontanigge, Sečoveljske soline, 1 os. (M. Sešllarpisno)

- 28. 9. 2017, Amerika, Ormoško jezero, 8 os. (L. Božıč, M. GAMSER pisno)

- 5.-10. 10. 2017, Amerika, Ormoško jezero, 2 ad. (L. BožIČpisno)

Kravja čaplja Bubulcus ibis $(34,97)^{1}$

- 17. 5. 2017, zadrževalnik Medvedce, 1 os. v svatovskem perju (D. BoRDJAN pisno)

- 18. 9. 2017, zadrževalnik Medvedce, 1 os. (M. GAMSERpisno)

- 20. 12. 2017-25. 1. 2018, Cerkno, 1 os. (D. VIDMARpisno)

\section{Mali klinkač Clanga pomarina $(8,8)$}

- 21. 5. 2017, Kozlarjeva gošča, Ljubljansko barje, 1 os. (ک̌́ER 2017)

\section{Veliki klinkač Clanga clanga $(25,27)$}

- 15. 11. 2017, zadrževalnik Medvedce, 1 1cy (BORDJAN 2017)

Kraljevi orel Aquila heliaca (9, 9)

- 12.3. 2017, Griško polje, Senožeče, 1 imm. (I. KLJUN pisno)

1 Od 1. 1.2015 ne obravnavamo več opazovanj iz Naravnega rezervata Škocjanski zatok, saj se vrsta tam redno pojavlja vse leto. / From 1 Jan 2015, the Committee no longer assesses records from Škocjanski Zatok Nature Reserve, where the species is regularly present throughout the year. 
Stepski lunj $(50,52)$

- 15. 4. 2017, zadrževalnik Medvedce, 1 ㅇ (D. BORDJAN pisno)

- 25.4.2017, Mengeš, $12 \mathrm{cy}$ (D. Bordjanpisno)

- 10. 9.-15. 9. 2017, Šikole, 1 ad. đ̊ (M. GAMSER pisno)

- 8. 11. 2017, Dolenje Jezero, Cerkniško jezero, $12 \mathrm{cy}+$ (M. GAMSER pisno)

Koconoga kanja Buteo lagopus

- 5. 2. 2017, Velike Bloke, 1 os. (A. KotNiK pisno)

- 4-17. 2. 2017, zadrževalnik Medvedce, do 3 os. (D. Bordjan, M. Gamser pisno)

- 8. 11.2017, letališče Lesce, 1 os. (B. Blažıč, B. Kozinc, A. Mulejpisno)

- 8. 11.2017, Bloke, 1 os. (P. Veenvliet pisno)

- 23.11.2017, Divača, 1 os. (M. Hariopisno)

- 2. 12.2017, zadrževalnik Medvedce, 1 lcy (D. BORDJANpisno)

Rjasta kanja Buteo rufinus $(7,7)$

- 29. 8.2017, Kalič, 1 os. (M. Gamserpisno)

Dular Charadrius morinellus $(19,42)$

- 22.-23. 9. 2017, planina Klek, Pokljuka, 1 os. (R. IsKRa pisno)

Kamenjar Arenaria interpres

- 11. 9. 2016, Amerika, Ormoško jezero, 3 os. (L. BožIČpisno)

Veliki prodnik Calidris canutus

- 7.8.2017, Fontanigge, Sečoveljske soline, 1 os. (A. BožIČ, M. SEŠLARpisno)

- 2. 9. 2017, Turnišče, Ptujsko jezero, 1 juv. (L. BožIČpisno)

- 3.9.2017, Fontanigge, Sečoveljske soline, 1 os. (M.Denac, A, Kotnik, M. Mlakar Medved, M. SEŠLARpisno)

- 18. 9.2017, Turnišče, Ptujsko jezero, 1 juv. (L. BožIČ, M. GAMSERpisno)

- 5.-6. 10. 2017, Ormoško jezero, 1 juv. (L. BožIČpisno)

Ploskokljunec Calidris falcinellus (12, 29)

- 29. 8.-3. 9. 2017, Fontanigge, Sečoveljske soline, 1 obr. (VREZEC \& FEKONJA 2018)

\section{Peščenec Calidris alba}

- $\quad$ 18. 8. 2017, Turnišče, Ptujsko jezero, 1 juv. (L. BožIČpisno)

- 18. 9.2017, zadrževalnik Medvedce, 1 juv. (M. GAMSER pisno)

- 25. 9. 2017, Pobrežje, Ptujsko jezero, 1 juv. (L. BožIčpisno)

Prekomorski prodnik Calidris melanotos $(4,4)$

- 6. 7. 2017, zadrževalnik Medvedce, 1 os. (M. GAMSERpisno)

\section{Čoketa Gallinago media $(15,15)$}

- 13. 9. 2017, Ig, Ljubljansko barje, 1 os. (M. Denacpisno)

Ploskokljuni liskonožec Phalaropus fulicarius $(6,6)$

- 3. 11. 2017, Turnišče, Ptujsko jezero, 1 ad. ô (kadaver; zbirka Prirodoslovnega muzeja Slovenije 2017/378) (A., E., G. VREZEC, P. VRH VREZEC pisno)

Triprsti galeb Rissa tridactyla

- 10. 11. 2017, zadrževalnik Medvedce, 1 1cy (M. GAMSERpisno)

Veliki galeb Larus marinus $(6,8)$

- 8.9.2017, Podova, 12 cy (M. Gamser pisno)

Lopatasta govnačka Stercorarius pomarinus $(4,5)$

- 18. 9. 2017, zadrževalnik Medvedce, 1 ad. (M. GAMSERpisno)

Bodičasta govnačka Stercorarius parasiticus $(11,11)$

- 23. 5. 2017, Ptujsko jezero, 1 ad. (temna oblika) (M. Gamserpisno)

- 26.7.2017, zadrževalnik Medvedce, $13 c y$ (M. GAMSERpisno)

Močvirska uharica Asio flammeus (33, 49)

- 28. 11. 2016-6. 3. 2017, Kozlarjeva gošča, Ljubljansko barje, do 14 os. (DenaC 2017c, HANŽEL 2017)

11. 2.-18. 4. 2017, zadrževalnik Medvedce, do 2 os. (T. Basle, D. Bordjan, M. Gamser pisno)

- 20.9.2017, zadrževalnik Medvedce, 1 os. (M. GAMSERpisno)

- 10. 11. 2017, zadrževalnik Medvedce, 1 os. (M. GAMSERpisno) 
Zlatovranka Coracias garrulus

- 16. 5. 2017, Brestovica pri Povirju, 1 ad. (Denac 2017b)

- 26.7.2017, Vodice, 1 ad. (BlAžIČ 2017a)

Rjavoglavi srakoper Lanius senator

- 13.5.2017, Lesce, 1 ○ (A. Mulejpisno)

19. 5. 2017, Prhajevo, Velike Lašče, 1 (Denac K. 2017)

- Kratkoprsti škrjanček Calandrella brachydactyla $(14,45)$

- 13.-14. 5. 2017, Ig, Ljubljansko barje, 2 os. (A. KoTnIKpisno)

Mušja listnica Phylloscopus inornatus $(19,19)$

- 27. 10. 2017, Lipe, Ljubljansko barje, 1 1cy obr. (VIDIC 2017)

Plevelna trstnica Acrocephalus agricola $(8,8)$

- 16.9.2016, Verd, Vrhnika, 1 1cy obr. (VREzeC \& FeKonja 2017)

- $\quad$ 31. 7.2017, Verd, Vrhnika, 1 1cy obr. (VREZeC \& FeKonja 2018)

Svetlooka penica Sylvia crassirostris $(3,3)$

- 8.4. 2017, Hrastovlje, 1 đ̆ (ŠERE 2017b)

Rožnati škorec Pastor roseus (16, 150)

- 23. 5. 2017, Naravni rezervat Škocjanski zatok, 1 os. (I. BRAJNIK pisno)

Snežni strnad Plectrophenax nivalis

- 13. 2. 2017, HE Brežice, 1 os. (D. KLENOVŠEK pisno)

Beloglavi strnad Emberiza leucocephalos $(18,19)$

- 23. 10. 2017, letališče Lesce, 1 ad. ô (BLAžIČ 2017b)

Mali strnad Emberiza pusilla $(22,22)$

- 13. 10. 2017, Bistrica, Šentrupert, 1 1cy (VRezec \& FeKonja 2018)

\section{Potrjena opazovanja iz kategorije D / Accepted Category $\mathrm{D}$ records}

Mala gos Anser erythropus $(0,0)$

- 17. 2.-18. 4. 2017, Družmirsko jezero, 1 os. (A. Bolčina, M. Gabor, J. Gojznikar, R. KRAŠEVEC pisno)

\section{Regionalne redkosti / Regional rarities}

Pritlikavi kormoran Microcarbo pygmeus

- 4.7.2017, Teharsko jezero, 1 os. (A. Božıč, M. GAMSERpisno)

Školjkarica Haematopus ostralegus

- 3. 5. 2017, Pobrežje, Ptujsko jezero, 1 ad. (L. BožIčpisno)

Srebrni galeb Larus argentatus

- 19. 2. 2017, Zbiljsko jezero, 1 2cy (M. SEŠLAR pisno)

Črnomorski galeb Larus cachinnans

- 27. 1. 2017, HE Moste, reka Sava, 12 cy (RUTNIK 2017)

- 11. 3. 2017, Fontanigge, Sečoveljske soline, 1 2cy (A. BožIČpisno)

Kaspijska čigra Hydroprogne caspia

- 6. 4. 2017, zadrževalnik Medvedce, 3 os. (B. BLAžıčpisno)

- 7. 4. 2017, Žovneško jezero, 2 os. (J. GoJZNIKARpisno)

Mala čigra Sternula albifrons

- 17. 5. 2017, Turnišče, Ptujsko jezero, 2 ad. (D. BORDJAN, L. BožIČ pisno)

- 23. 5.2017, Turnišče, Ptujsko jezero, 1 ad. (M. GAMSER pisno)

- 10. 9. 2017, Amerika, Ormoško jezero, 3 ad. w./1cy (L. BožIČpisno)

Taščična penica Sylvia cantillans

- 19. 5. 2017, Žovneško jezero, 1 o (J.LESKošEK pisno)

Rjava cipa Anthus campestris 
- 6. 5. 2017, Ptujsko jezero, 2 os. (B. Blažıč, A. Božič, M. Denac, R. Lobnik, M. Mlakar Medved, M. SEŠLARpisno)

\section{Potrjena opazovanja iz kategorije C / Accepted Category $\mathrm{C}$ records}

Brkati ser Gypaetus barbatus $(4,4)$

- 17. 6. 2017, Velika Zelnarica, 1 1cy (DenaC 2017a)

\section{Potrjena opazovanja iz kategorije E / Accepted Category E records}

Tibetanska gos Anser indicus $(4,5)$

- 12. 4. 2009, Hraške mlake, Smlednik, 1 os. (M. Cerarpisno)

Moškatna bleščavka Cairina moschata $(76,194)$

- 28. 12. 2017, zadrževalnik Medvedce, 1 os. (A., E., G. VRezec, P. VRH VReZec pisno)

Nevestica Aix sponsa $(22,24)$

- 14. 1.2017, Gazice, Cerklje ob Krki, 3 os. (1 3, 2 q) (G. Bernard, A. BožIČ, J. Vidmarpisno)

- 16. 2. 2017, Ptujsko jezero, 1 + (M. GAMSER pisno)

- $\quad$ 18. 2. 2017, Nova Gorica, 1 đ̆(S. Tzarpisno)

Mandarinka Aix galericulata

- 14. 1. 2017, Gazice, Cerklje ob Krki, 1 ○ (G. BERnard, A. BožIČ, J. Vidmarpisno)

- 27. 1.2017, Trnovo, reka Ljubljanica, Ljubljana 1 ( M. GABERŠEK pisno)

- 29. 1.2017, Lent, Maribor, reka Drava, 1 o (M. SEŠLARpisno)

Virginijski kolin Colinus virginianus $(8,18)$

- 5.6.2017, Sečovlje, 1 os. (A. Božıčpisno)

Klavžar Geronticus eremita $(12,21)$

- $\quad$ 5. 6. 2017, Groblje pri Prekopi, Šentjernejsko polje, 1 os. (E. ŠInkEC pisno)

- 6.6.2017, Vopovlje, Cerklje na Gorenjskem, 1 os. (B. BlažIČ, M. SEŠLARpisno)

- 1. 7.-8. 7. 2017, Kranj, 1 os. (M. BEŽEK, G. Ceferin pisno)

- 22. 8. 2017, letališče Lesce, 1 os. (G. Kobler pisno)
Aleksander Psittacula krameri $(6,12)$

- 28. 1. 2017, Fužine, Ljubljana, 1 os. (I. A. Božıčpisno)

Zebrica Taeniopygia guttata $(0,0)$

- 6. 7. 2017, Ig, Ljubljansko barje, 1 os. (E. GAŠPARIČpisno)

\section{Zavrnjena opazovanja / Rejected records}

Leta 2017 ni bilo zavrnjenih opazovanj. / There were no rejected records in 2017.

\section{Summary}

This report by the Slovenian Rarities Committee presents records of rare bird species in Slovenia in 2017, with some addenda for previous years. The numbers in brackets refer to the number of records (first number) and individuals (second number) recorded between 1 Jan 1950 and 31 Dec 2016. Since 1 Jan 2013, submission to the Committee has been required for 37 additional species, 17 of which are regional rarities. Records of these species are not numbered, since records from previous years were not collected by the Committee. The Barnacle Goose Branta leucopsis was first recorded in Category $\mathrm{A}$, in addition to previous Category $\mathrm{D}$ and $\mathrm{E}$ records. Other notable observations were the third record of Red-breasted Goose Branta ruficollis, fifth records of Lammergeier Gypaetus barbatus and Pomarine Skua Stercorarius pomarinus, and seventh records of Greater Blackbacked Gull Larus marinus and Red Phalarope Phalaropus fulicarius. The list of birds recorded in Slovenia (as of 31 Dec 2017) contains 390 species (375 in Category A, 6 in Category B, 9 exclusively in Category C; 4 species are both in Categories A and C). Category D contains 7 species, while Category E contains 39, two of which are classified into Subcategory E*. These two categories are not part of the list.

\section{Literatura}

BLAžIČ B. (2017a): Zlatovranka Coracias garrulus. Acrocephalus 38 (174/175): 220-221. 
BLAžIČ B. (2017b): Beloglavi strnad Emberiza leucocephala. - Acrocephalus 38 (174/175): 226.

Bordjan D. (2017): Veliki klinkač Aquila clanga. Acrocephalus 38 (174/175): 218.

BožIČ L. (2017): Rezultati januarskega štetja vodnih ptic leta 2017 v Sloveniji. - Acrocephalus 38 (174/175): 203-215.

DeNAC K. (2017): Rjavoglavi srakoper Lanius senator. Acrocephalus 38 (172/173): 71 .

Denac M. (2017a): Brkati ser Gypaetus barbatus. Acrocephalus 38 (172/173): 63-64.

DenaC M. (2017b): Zlatovranka Coracias garrulus. Acrocephalus 38 (172/173): 65.

Denac M. (2017c): Močvirska uharica Asio flammeus. Acrocephalus 38 (172/173): 66-67.

Gill F., Donsker D. (eds.) (2018): IOC World Bird List (v 8.2). DOI: 10.14344/IOC.ML.8.2. - [www. worldbirdnames.org], 10/12/2018.

HaNžEL J. (2016): Redke vrste ptic v Sloveniji v letu 2015 - Poročilo Nacionalne komisije za redkosti. Acrocephalus 37 (168/169): 69-78.

HANŽEL J. (2017a): Redke vrste ptic v Sloveniji v letu 2016 - Poročilo Nacionalne komisije za redkosti. Acrocephalus 38 (172/173): 21-30.

Hanžel J. (2017b): Sredozemski viharnik Puffinus yelkouan. - Acrocephalus 38 (174/175): 218.

HanžEL J., ŠERE D. (2011): Seznam ugotovljenih ptic Slovenije s pregledom redkih vrst. - Acrocephalus 32 (150/151): 143-203.

PolJANec L. (2017): Ledni slapnik Gavia immer. Acrocephalus 38 (174/175): 217-218.

RUTNIK K. (2017): Črnomorski galeb Laruscachinnans. Acrocephalus 38 (174/175): 220.

ŠERE D. (2017a): Mali klinkač Aquila pomarina. Acrocephalus 38 (172/173): 65.

ŠERE D. (2017b): Svetlooka penica Sylvia crassirostris. Acrocephalus 38 (172/173): 69.

VIDIC B. (2017): Mušja listnica Phylloscopus inornatus. Acrocephalus 38 (172/173): 70.

VRezec A., Fekonja D. (2017): Poročilo o obročkanju ptic v Sloveniji v letu 2016 in pojavljanje mušje listnice Phylloscopus inornatus v zadnjih 25 letih v Sloveniji. - Acrocephalus (174/175): 171-202.

VRezec A., Fekonja D. (2018): Poročilo o obročkanju ptic v Sloveniji leta 2017 in kratek pregled barvnega obročkanja v obdobju 2012-2017. - Acrocephalus 39 (178/179): 129-163.

Prispelo / Arrived: 5. 2. 2019

Sprejeto / Accepted: 3. 3. 2019 


\section{DODATEK 1 / APPENDIX 1}

Dokumentarne fotografije izbranih opazovanj iz leta 2017, ki doslej še niso bile objavljene v slovenskih tiskanih virih z navedenim krajem, datumom in številom osebkov.

Documentary photos from 2017, so far unpublished in Slovenian printed sources with site name, date and number of individuals given.

(1)

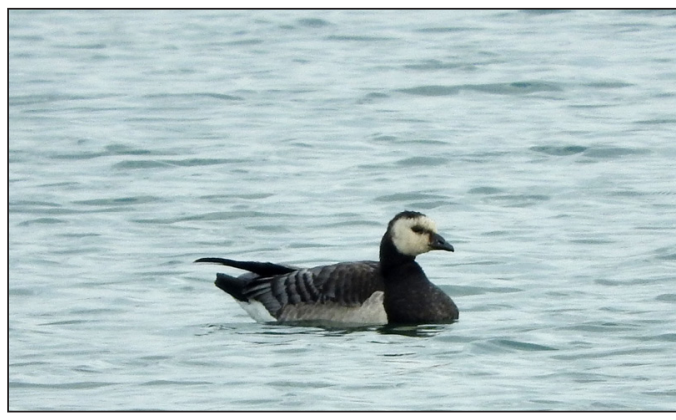

(3)

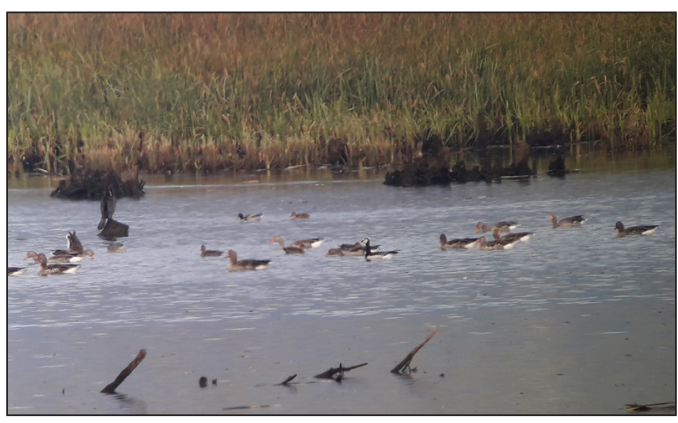

(5)

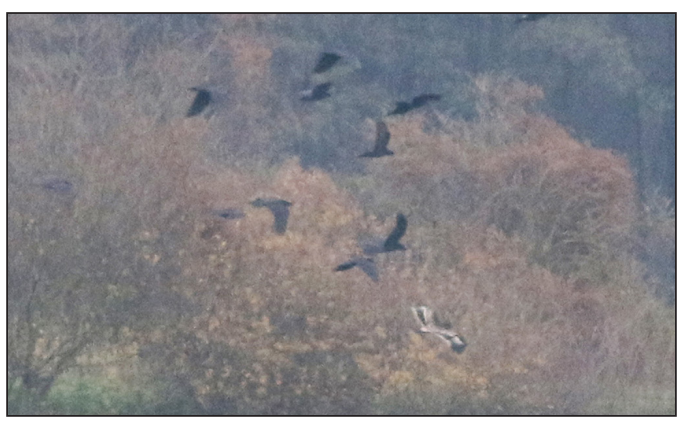

(2)

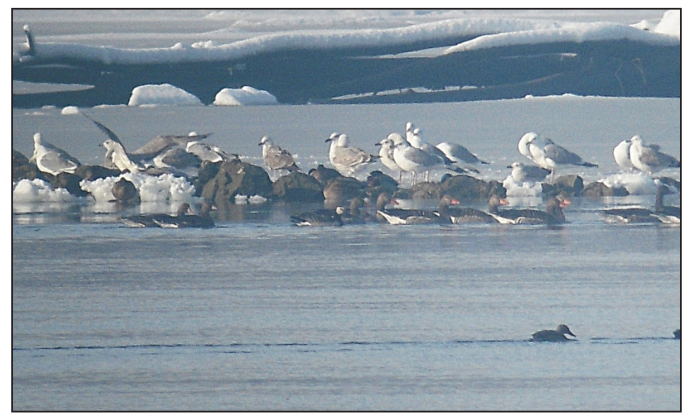

(4)

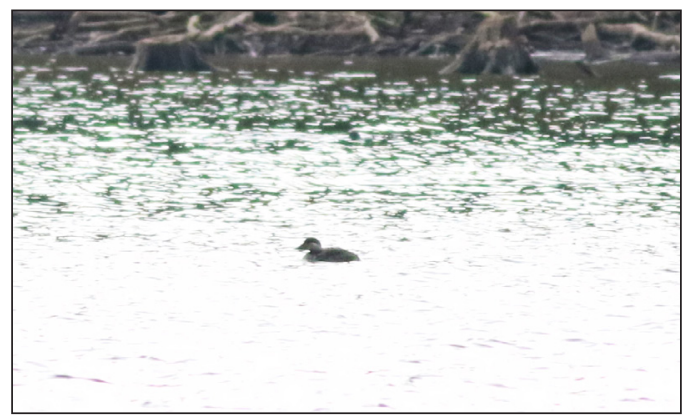

(6)

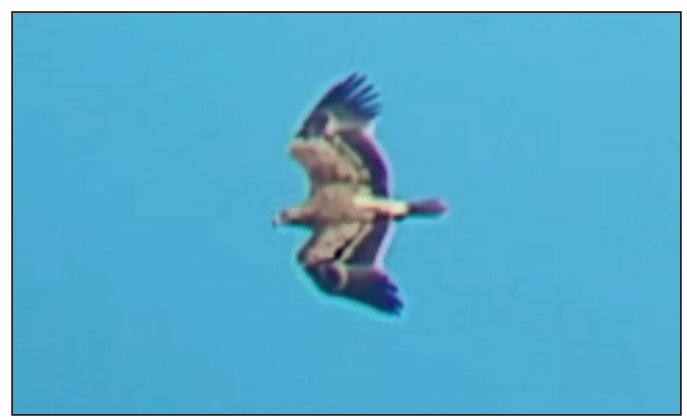

Slike 1-6 / Figures 1-6: (1) belolična gos Branta leucopsis, 12. 1. 2017, Babinci (foto: R. Šiško); (2) belolična gos Branta leucopsis, 14. 1. 2017, Ormoško jezero (foto: L. Božič); (3) beloličña gos Branta leucopsis, 28. 10. 2017, zadrževalnik Medvedce (foto: E. Horvat); (4) črna raca Melanitta nigra, Žovneško jezero, 22. 2. 2017 (foto: J. Novak); (5) veliki klinkač Clanga clanga, 15. 11. 2017, zadrževalnik Medvedce (foto: D. Bordjan); (6) kraljevi orel Aquila heliaca, 12. 3. 2017, Griško polje, Senožeče (foto: I. Kljun). 
Nadaljevanje dodatka 1 / Continuation of Appendix 1

(7)

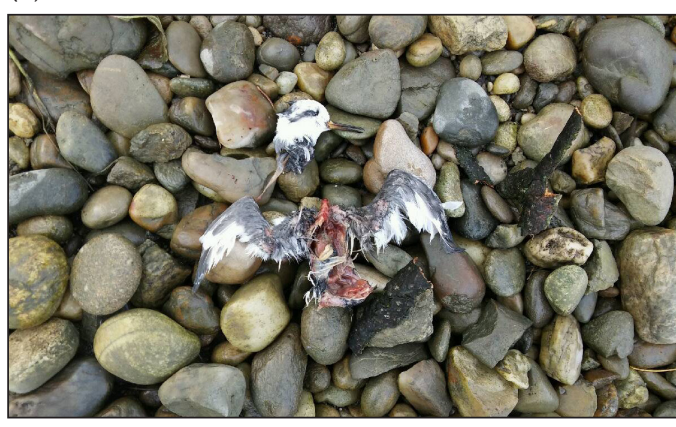

(9)

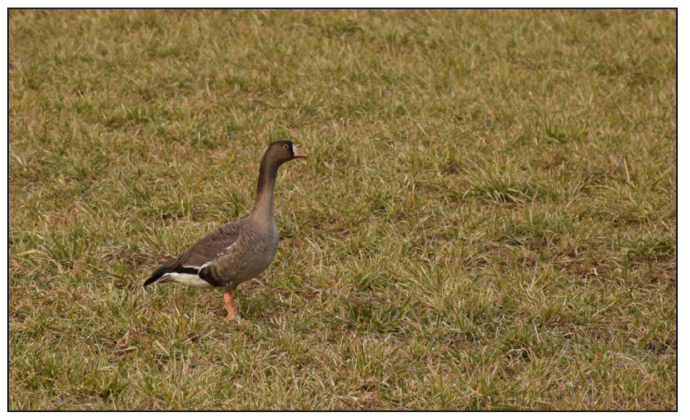

(8)

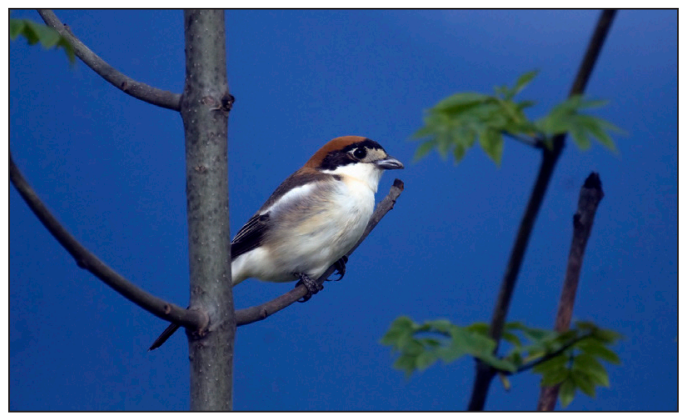

(10)

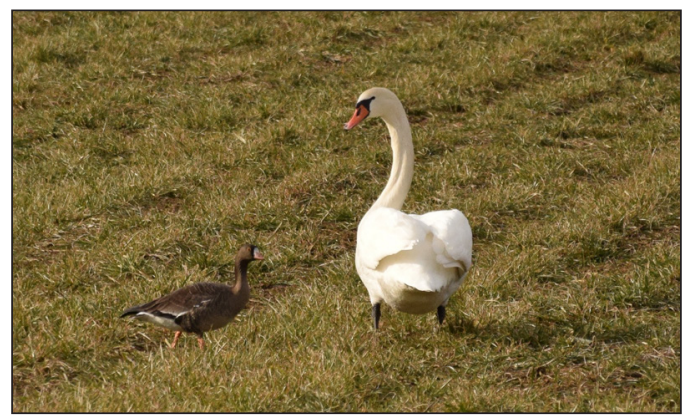

Slike 7-10 / Figures 7-10: (7) ploskokljuni liskonožec Phalaropus fulicarius, 3. 11. 2017, Ptujsko jezero (foto: A. Vrezec); (8) rjavoglavi srakoper Lanius senator, 13. 5. 2017, Lesce (foto: A. Mulej); (10-11) mala gos Anser erythropus, 17. 2. 2017, Družmirsko jezero (foto: J. Gojznikar 